\title{
Concept-H: Sustainable Energy Supply
}

\author{
Jure Margeta ${ }^{1}$, Zvonimir Glasnovic ${ }^{2, *}$ \\ ${ }^{1}$ University of Split, Faculty of Civil and Architectural Engineering, 21000 Split, Matice Hrvatske 15, Croatia, \\ ${ }^{2}$ University of Zagreb, Faculty of Chemical Engineering and Technology, 10000 Zagreb, Savska 16, Croatia, \\ Corresponding author.Tel.: +385-1-4597108; Fax:+385-1-4597260,E-mail: zvonglas@fkit.hr
}

\begin{abstract}
The paper presents an innovative solution that combines Pump Storage Hydroelectric (PSH) with power plants that use only Renewable Energy Sources (RES) into a unique energy producing technological system, called Concept-H, which combines PV, solar thermal and wind power plants with PSH. The basic difference between Concept- $H$ and the previous use of RES, where output energy depends on the fluctuating input energy, lies in the fact that such new concept can continuously and safe supply a consumer with electric energy and power. In this sense RES are put in equal position with conventional energy sources and Concept-H promises to be the important building element of the future sustainable power system as a green strategy of electric energy production. The application of Concept- $H$ creates a significantly lower risk for humans and the environment, than when using conventional technologies, especially in possible incidental situations. The proposed solution is flexible for realization and can be applied in different climatic, hydrological and physical conditions where people live.
\end{abstract}

Keywords: Concept-H, Renewable Energy, Hydroelectric Energy, Sustainable Energy Supply, Green Energy Scenario

\section{Introduction}

This paper analyses the possible development of the renewable electricity scenario, based on the strategy of the use of Renewable Energy Sources (RES), called Concept-H [1]. This concept is based on the use of renewable resources and the use, directly or indirectly, of water storage of hydroelectric (HE) plants as energy storage in addition to other technological possibilities which increase continuity of supplies of RES energy to Electric Power System (EPS). In addition to direct connection of RES with EPS and the users, Fig. 1 (a), the proposed approach in the development of continuous green energy supply also requires indirect connection by use of hydro energy power production unit, similar to Pump Storage Hydroelectric Plant (PSH), Fig. 1 (b).

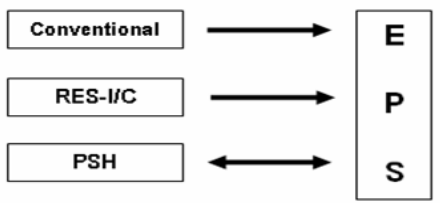

(a)

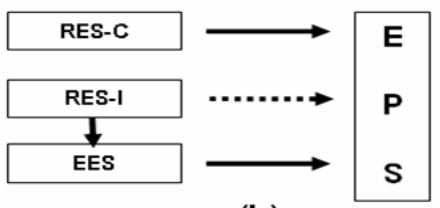

(b)
Figure 1. (a) Conventional connection of energy source and storage; (b) principle concept which would enable the green energy scenario (RES-I: intermittent RES; RES-C: continuous RES; EES: Electric Energy Storage, i.e. water storage).

Thus, the approach that enables the realization of green energy scenario would mostly be based on the concept of serial connection between green energy source and EPS through water storage of HE power plant, i.e. PSH, as shown in Fig. 1 (b). In this sense the future sustainable EPS or specific users, i.e. those based solely on RES, would have the configuration as in Figure 2. Solar (PV and solar thermal) and wind power plants, including 
other non-continuous energy sources, would connect serially/indirectly to EPS and users through Electric Energy Storage (EES), i.e. water storage, while HE, geothermal and biomass power plants would connect directly, because they can provide continuous supply to consumers.
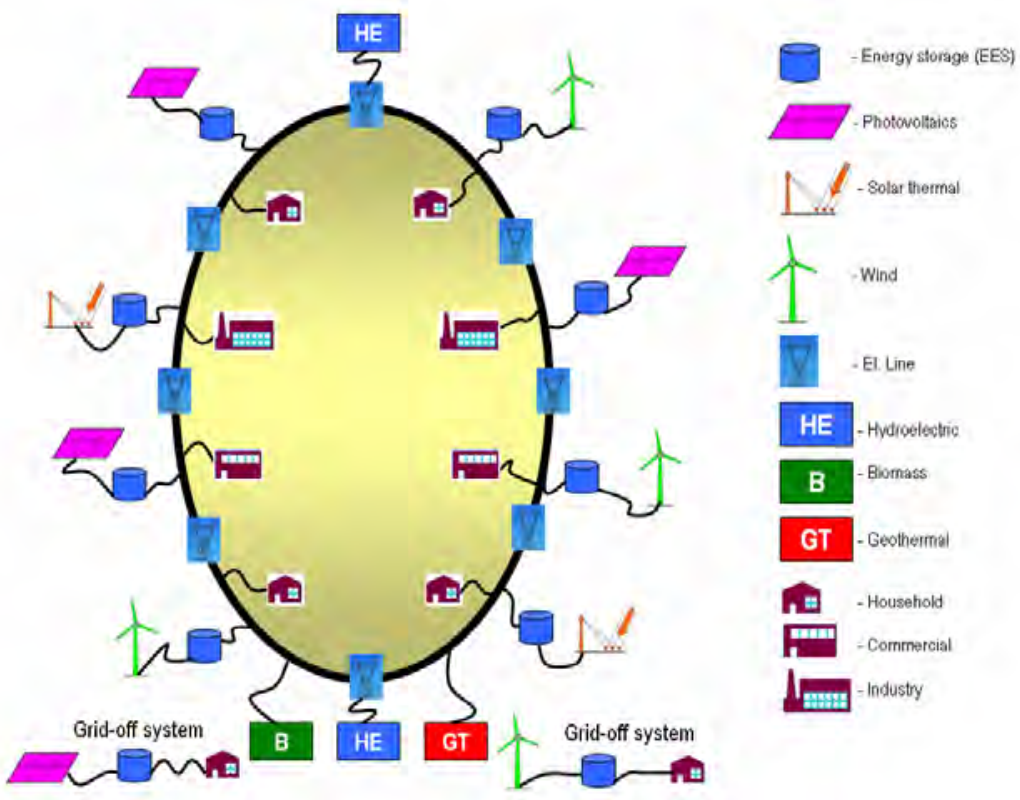

Figure 2. Vision of the future fully sustainable electric power system.

Renewable energy sources with occasional work will also be used directly through global and regional electric supply network, if and when it is acceptable for the electric power system. In this way water storage of hydroelectric power plants has the most significant role in realization of the green system, [2]. Numerous technologies of energy storage are known today (batteries, flywheel, pressure vessels, etc.), which differ in: size, energy storage costs, efficiency, lifetime, costs per cycle, etc., [3, 4]. It is well known that none of the present-day technologies could, in terms of ratings, be compared to storage by PSH, [4]. Precisely because of that, the concept of PSH is still the most significant EES today, which is a mature technology with large volume, long storage period, high efficiency and reliability, while capital cost per unit of energy is low, [5]. For this reason, with the present-day technology, it is possible to achieve the vision of continuous green energy production through Concept- $H$ [1].

Implementation of this concept will depend primarily on the policy towards renewable energy sources, RES technological development, and economic conditions. Energy produced from RES is still significantly more expensive than conventional and therefore its production is subsidized. Therefore, the Concept- $H$ in its initial implementation should be used primarily for daily energy peak shaving with a tendency towards daliy load leveling. Such implementation strategy would have the greatest ecological and economic effect.

\section{Main settings of the proposed concept}

\subsection{Main elements of Concept-H}

In the green scenario (Figure 2) continuous renewable energy sources (RES-C) are exploited directly, while intermittent energy sources, such as marine, wind and solar renewable energy sources (RES-I) are exploited indirectly through Concept-H. RES-I power plants deliver their energy to the Pump Station (PS) which pumps water into storage of HE power plants which then serve for daily, weekly and seasonal energy storage, while the consumer is supplied from 
the associate PSH power plants, transforming intermittent energy supply into continuous and manageable energy supply as conventional storage of HE power plants, [6, 7]. Serial connection is based on two pipelines in classical concept of PSH. One pipeline pumps water from lower water resource into upper storage when RES produce energy and the other conveys water from the upper storage to turbines for production of hydro energy in accordance with the consumers' needs. In this way intermittent operation of RES-I does not affect hydro energy production according to the consumers' needs. In the proposed Concept$H$, PSH is used for continuous production of energy, or energy storage for daily and seasonal peak load shaving.

The key driving elements of the solution are: (i) RES-I; (ii) energy storage unit (pump station and water storage); (iii) HE. Production and consumption balancing is performed in upper storage based on balance equation of storage volume and HE productivity, Figure 3. RES power plants are also in parallel (direct) connection with the regional EPS, because it is logical that RES-I power plant will directly deliver its energy excesses into the system, i.e. when the upper storage is full. It is also logical that energy surpluses in EPS are used for PSH operation.

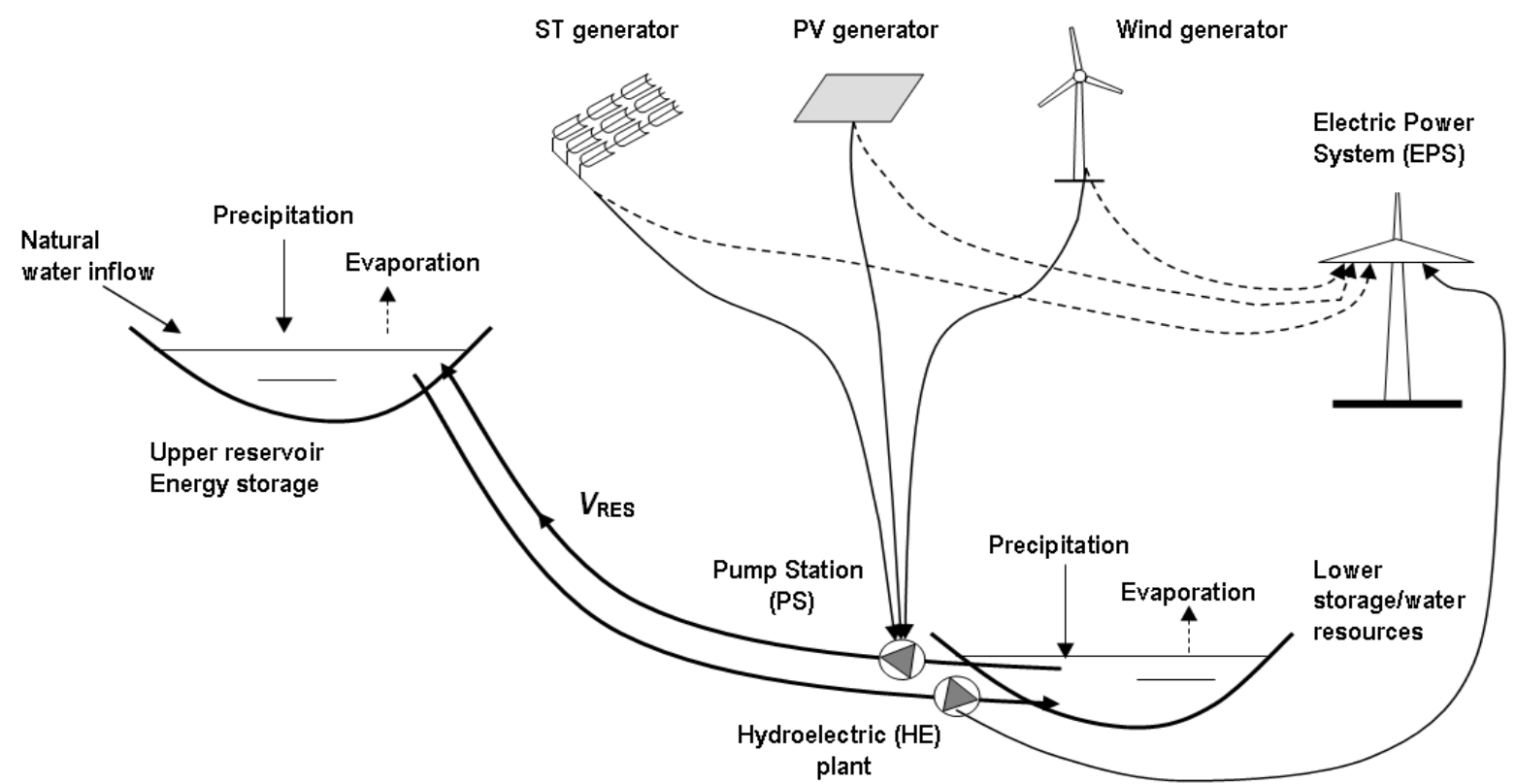

Fig 3. Concept-H: Hybrid power unit as the main building element of the future green energy scenario.

In this concept, water storages in energy power systems operate as energy storage. Hydroelectric power plants are very flexible and manageable in their work and quickly adapt to the needs of EPS. The biggest problems occur when hydrological conditions are not satisfactory. This problem is solved with the proposed Concept- $H$, because new non-natural water resources are created.

The basic unit for continuous production of energy is the hybrid power plant RES-PSH (i.e. Concept-H). Hybridization can be applied to all RES-I energy sources, the most promising being with solar energy because, unlike wind power plants, it is a reliable source of energy, available at all locations where people live. In addition, solar energy enables rational daily balancing of energy production and consumption and thus the need for construction of small storage of PSH. Hybridization can be carried out with other sources of RES indirectly through energy system network. 
The proposed solution is characterized by balance of energy and water. Energy balance of the hybrid electric power plant or the single time step is:

$$
E_{h y b(i)}=E_{h y b(i-1)}+E_{P S H(i)}+E_{D R E S(i)}
$$

Where $E_{\text {hyb(i) }}$ and $E_{\text {hyb(i-1) }}$ are hybrid energy production in time stage $i$ and $i$-1 respectively, $E_{\mathrm{PSH}(\mathrm{i})}$ is energy produced from PSH/HE, $E_{\mathrm{DRES}(\mathrm{i})}$ is energy which RES source supply directly to the energy power system in time period $i$. However, unlike $E_{\mathrm{PSH}(\mathrm{i})}$ which is reliable and manageable energy production, this energy supply is random, independent and uncontrollable energy production and thus is of minor importance for the EPS. Total energy production is:

$$
E_{h y b}=\sum_{i=1}^{T} E_{h y b(i)}
$$

Where $T$ is total period used for production of energy (year).

Losses occur in energy transfers from one to the other $\left(E_{R E S-I}\right.$ into $\left.E_{P S H}\right)$, as well as in transport from the source to EPS. Total production losses $\Delta E$ period $T$ are:

$$
\triangle E=E_{R E S-I}-E_{P S H}-E_{D R E S} .
$$

Losses due to energy transfer are inevitable and are the price paid for the sustainable and new quality in green energy production, Figure 3.

Water is the second resource needed for constant plant work. Water is necessary for filling of the system and compensation of losses due to evaporation, leakage and the like. Once fully filled, the system needs regular compensation of losses. Given that the system is integrated in the surroundings, part or all losses can be compensated by natural hydrological processes (precipitation, water inflow from catchment areas, etc.), or improved in special situations by external transfer of water mass inflow in the upper storage.

\subsection{Water storage as energy storage}

The equivalent reservoir energy balance for a single time step $i$ is expressed as:

$$
E_{P S H(i)}=E_{P S H(i-1)}+E_{\text {nat }(i)}+E_{R E S(i)}-E_{\text {prod }(i)}-E_{\text {evap }(i)}-E_{\text {loss }(i)}
$$

Where $E_{\mathrm{PSH}(\mathrm{i})}$ is the total equivalent reservoir stored energy in time period $i$ and $i-1$ (MWh); $E_{\text {nat(i) }}$ is the total natural potential energy inflow over time period $i(\mathrm{MWh}) ; E_{\mathrm{RES}(\mathrm{i})}$ is the total energy inflow over time period $i$ (MWh) generated (pumped) by energy from RES; $E_{\text {prod(i) }}$ is the decision variable or the total energy outflow over time period $i(\mathrm{MWh})$; and $E_{\text {evap(i) }}$ and $E_{\text {loss(i) }}$ is the energy outflow corresponding to the losses (evaporated volume and other losses) from the equivalent reservoir over time period $i$ (MWh).

$E_{\text {nat(i) }}$ during time period $i$ is the sum of all reservoir natural potential energy inflows (river, rain). For a single reservoir, it is calculated by multiplying the natural water inflow discharge $\left(Q_{\text {nat(i) }}\right)$ by its mean productivity $(\xi)$. Consumptive use water discharges $(Q C)$ must be subtracted from the natural inflows. Thus $E_{\text {nat(i) }}$ is expressed as:

$$
E_{\text {nat }(i)}=\xi\left(Q_{\text {nat }(i)}-Q C_{(i)}\right) .
$$

$E_{\mathrm{RES}(\mathrm{i})}$ during time period $i$ is the sum of all reservoir artificial potential energy inflows (RES). For a single reservoir, it is calculated by multiplying the artificial-RES water inflow discharge $\left(Q_{\mathrm{RES}(\mathrm{i})}\right)$ by its mean productivity: 


$$
\begin{aligned}
E_{R E S(i)} & =\xi \cdot Q_{R E S(i)}, \\
Q_{R E S(i)} & =\frac{E_{R E S}}{C F \cdot t \cdot\left(\rho \cdot g \cdot H_{n(P S)} \cdot \eta_{P S} \cdot \eta_{I N V}\right)}=\frac{E_{R E S}}{C F \cdot t \cdot \xi_{M P I}},
\end{aligned}
$$

where $H_{\mathrm{n}(\mathrm{PS})}$ is net head of pump station, $\eta_{P S}$ is total available efficiency of pump station, $\eta_{\mathrm{INV}}$ efficiency of inverter and $\zeta_{\text {MPI }}$ is motor, pump and inverter productivity and $t$ is time period. The energy outflow from the equivalent reservoir is the decision variable in the optimization problem, i.e. the desired energy production.

\subsection{Relation between electric power of the RES generator and storage}

The calculation of nominal power $P_{\mathrm{el}}$ for pumping water into upper storage and covering the demand for energy in a PSH in time step $i$ is performed according to the characteristics of RES-I power plants (wind, PV and solar thermal). The equation for electric power of a RES-I generator (PV, ST or $\mathrm{W}$ ) is derived from the equation used for dimensioning of the PV generator, presented in the paper [6] and which can generally be expressed as follows:

$$
P_{\mathrm{el}(i)}=\frac{2.72 \cdot 10^{-3} \cdot p_{R E S} \cdot H_{T E(i)}}{\eta_{R E S(i)}\left(T_{a}, v, \rho, \varphi\right) \cdot \eta_{M P I} \cdot E_{R E S(i)}} \cdot V_{R E S(i)},
$$

where $p_{\text {RES }}\left(\mathrm{W} / \mathrm{m}^{2}\right)$ is equivalent value of RES-I power reference value (for solar systems it is $\left.1000 \mathrm{~W} / \mathrm{m}^{2}\right) ; \eta_{\text {MPI }}$ is efficiency of motor-pump unit and inverter; $\eta_{\operatorname{RES}(\mathrm{i})}\left(T_{\mathrm{a}}, v, \rho, \varphi\right)$ is exploitation efficiency of a RES, which depends on air temperature $T_{\mathrm{a}}$, density $\rho$, wind velocity $v$ and air humidity $\varphi ; H_{\mathrm{TE}(\mathrm{i})}(\mathrm{m})$ is total head, $V_{\mathrm{RES}(\mathrm{i})}\left(\mathrm{m}^{3}\right)$ is total water volume to be pumped by RES-I power plant into upper storage in order to satisfy daily energy consumption; $E_{\mathrm{RES}(\mathrm{i})}\left(\mathrm{kWh} / \mathrm{m}^{2} /\right.$ day $)$ is average daily energy from RES-I, available for energy production. Optimal power $P_{\mathrm{el}}$ * could be calculated in the similar way as is shown in the paper [6].

Apart from $E_{\mathrm{RES}}$ and the size of the consumer, expressed in Eq. (8) by $V_{\mathrm{RES}(\mathrm{t})}$, it can be seen that upper storage volume $V$ also has a dominant effect on $P_{\mathrm{el}}$. The dependence of $P_{\mathrm{el}}$ on operating volume $V$ of the upper storage is:

$P_{e l}=-a \cdot \operatorname{Ln}(V)+b$,

Where $P_{\text {el }}$ is power of RES-I (W), $V$ is operational volume storage $\left(\mathrm{m}^{3}\right), a, b$ - coefficients based on location and technological features. This relationship has been determined by the previous papers for PV and ST hybrid power plants, such papers have not yet been made for the wind power plants.

The interval $V_{\min }<V<V_{\max }$ which is called the boundary layer, serves as transition from the $P_{\max }$ value to the value $P_{\min }$. Minimal value $P_{\min }$ is conditioned by the possibility of construction of storage $\left(V_{\max }\right)$ at a location. Therefore:

$\left.P\right|_{V=V \max }=P_{\min }$.

As the period of daily insolation is always shorter than the daily period of planned energy production (24 hours), the minimum period of daily insolation, compared to the planned production of energy, determines the minimum dimensions of the storage volume and thus the maximum required power of solar power plant is:

$\left.P\right|_{V=V \min }=P_{\max }$. 
The boundary layer defines the size of storage volumes necessary to ensure the continuity of the planned production.

The constant " $b$ " represents the maximum power of the plant that provides the total energy needed in the critical time step of the analysis period. The constant " $a$ " represents the cumulative impact of factors for production of solar energy (technological and climate) in the period considered.

$P_{\mathrm{el}}$ and $V$ are optimized according to characteristics of the problem. Based on the results of modelling it is possible to obtain more detailed information of interest to decision-making. Since the functional relationship between $P_{\mathrm{el}}$ and $V$ is known (equation (9)), as well as the relationship between $P_{\mathrm{el}}$ and the area of collector field $A$ of PV generator, it is possible to obtain the connection between the required $A$ and $V$, according to:

$$
A=\frac{P_{e l}}{1000 \cdot \eta_{o c}}=\beta \cdot(-a \cdot \operatorname{Ln}(V)+b)\left(\mathrm{m}^{2}\right)
$$

Where $\eta_{\text {oc }}$ is PV generator efficiency.

In this way, relations are obtained for the size of the three key structures of the hybrid PVPSH power plant, the area of the collector field $(A)$, power of the PV generator $\left(P_{\mathrm{el}}\right)$ and the working volume $(V)$. The results for Solar Thermal (ST) power plant can be obtained in the similar way.

Other objects of interest for the sizing of the system are pumping station PS and HE. The capacity of pump station $Q_{\mathrm{PV}}$ is obtained based on modelling results as dependent variable used for evaluating the performance of the system, and HE capacity is set by building objectives.

The relation between $P_{\mathrm{el}}$ and $V$ can also be observed through the required reserve power supply in the system. It is obvious that the upper storage has the key role in the proposed hybrid power plant management. Relation between $P_{\text {el }}$ of RES-I power plants (PV and ST) and reservoir volume $V$ and the required $P_{\text {el }}$ depending on power supply reserve, Figure 4.

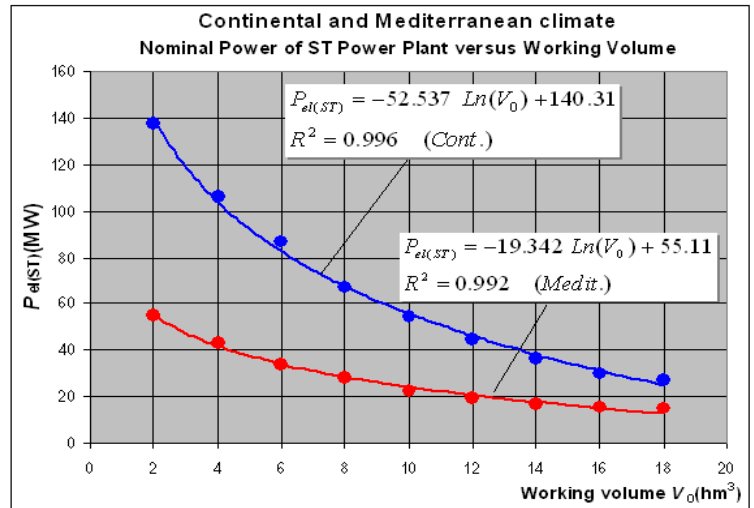

a) ST generator

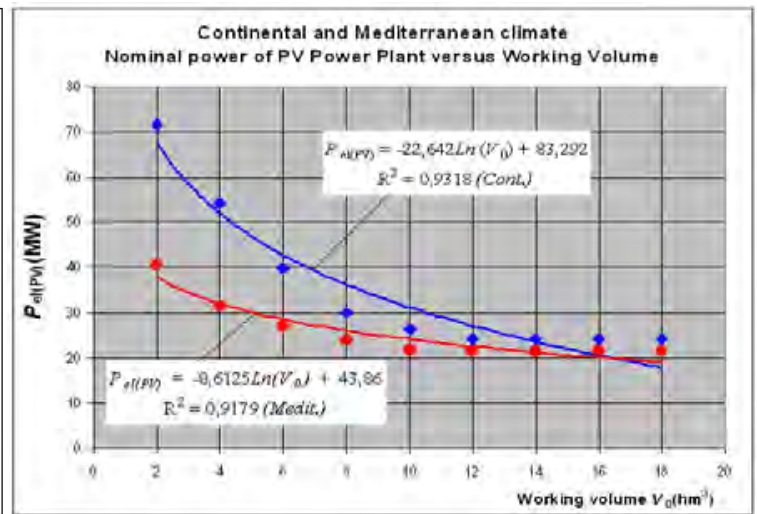

b) PV generator

Fig 4. Characteristic curves $P_{\mathrm{el}}=f(V)$ for $S T$ and $P V$ power plants for two climates areas.

\section{Possible applications}

Since this is a completely innovative solution, there are no practical results and the basic relationships of interest for the development and application can be obtained on the basis of previous research, basic theoretical assumptions and literature data. Key data relate to the 
basic dimensions of power plant and its parts, production features, as well as economic, social and environmental impacts. Previous research [6, 7] shows that for Mediterranean climate (Island of Vis in Croatia) and continental climate conditions (Osijek, Croatia), the size of the hybrid system in the case of PV generator for these areas can be determined based on equations:

$$
\begin{aligned}
& P_{P V(\text { Medit. })}=-10.497 \operatorname{Ln}(V)+44.21 \\
& P_{P V(\text { Cont. })}=-19.904 \operatorname{Ln}(V)+65.123
\end{aligned}
$$

If these results were applied to the EPS, a general framework and dimensions of the solution could be obtained, using the Concept-H. The same was done in the case of Croatia [8], so that the reality of achievement of green energy policies [8] could be seen in Figure 5.

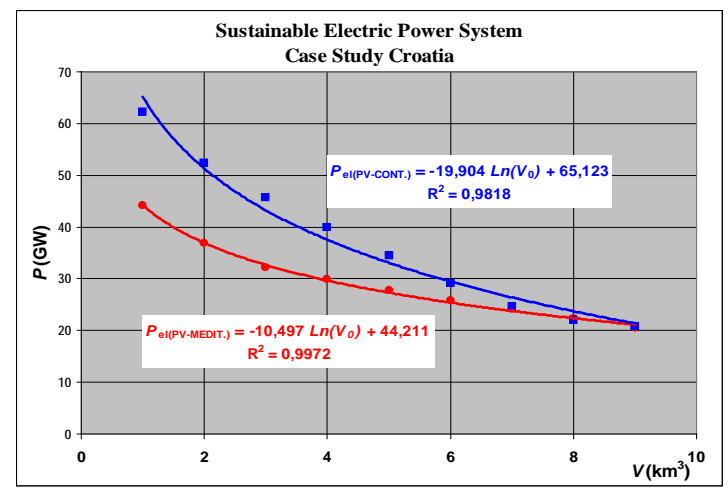

Fig 5. Scenario for Croatia.

In this way the possible applicability of the Concept- $H$ at different locations and regions could be analyzed. The proposed Concept- $H$ locally imitates the natural hydrological process, essentially generated by the same natural forces (solar energy and gravity), and, as a mostly closed system based on the use of natural renewable solar energy, it has a significantly smaller impact on the environment than other energy sources. In its operation it does not consume water, organic or other substances, does not create harmful residues and $\mathrm{CO}_{2}$, and therefore provides opportunities to achieve sustainability objectives.

\section{Comments and conclusions}

This paper points to the possibility of realization of green energy scenario $[8,9,10]$ by a concept, the so-called Concept-H [1]. It is a technological concept of hybrid RES-PSH systems which provides continuous energy production, the same as conventional energy sources. The solution in the proposed hybrid concept RES+PSH represents a production unit of sustainable energy supply based on natural resources which are free of charge and constantly available. The concept is very flexible in operation and construction. The accent is on hydroenergy, i.e. PSH as the main building unit, because this concept is flexible in implementation and provides continuous supply of „green“ energy and can be built in a wide range of climate areas, locations and water resources (fresh water, water with temporary flow, as well as on the sea). It can be implemented on the existing HE. The proposed production unit usually has very small impacts on the environment because it causes minimal changes in local and global hydrology and eco systems, and has a low level of potential danger for people and environment in case of incidental situations. Starting from the expected progress in the development of RES, especially PV [11], the proposed Concept-H may be one of the most promising solutions for achieving sustainable green energy scenario. 


\section{References}

[1] Z. Glasnovic, J. Margeta, Vision of total renewable electricity scenario, Renewable and Sustainable Energy Reviews, (2011), doi: 10.1016/j.rser.2010.12.016 (in press).

[2] B. Lee, D. Gushee, Massive electricity storage, An AIChE White Paper, American Institute of Chemical Engineers, 3 Park Avenue, New York, NY 10016, 2007.

[3] H.Chen, T.N. Cong, , W. Yang, C. Tan, Y. Li, Y. Ding, Progress in electrical energy storage system: A critical review. Progress in Natural Science, 19, 2009, pp. 291-312.

[4] ESA, Electricity Storage Association, Energy storage technologies. Technologies \& Applications - Technology Comparisons, 2009.

[5] J.P. Deane, B.P. Ó Gallachóir, E.J. McKeogh, Techno-economic review of existing and new pumped hydro energy storage plant, Renewable and Sustainable Energy Reviews, 14, 2010, pp. 1293-1302.

[6] Z. Glasnovic, J. Margeta, The features of sustainable Solar Hydroelectric Power Plant, Renewable Energy 34, 2009, 1742-1751.

[7] J. Margeta, Z. Glasnovic, Feasibility of the green energy production by hybrid solar + hydro power system in Europe and similar climate areas. Renewable and Sustainable Energy Reviews, 14, 2010, pp. 1580-1590.

[8] Z. Glasnovic, J. Margeta, Sustainable Electric Power System, Is It Possible? - Case Study Croatia, Journal of Energy Engineering 136, 2010, pp. 103-113.

[9] EREC, European Renewable Energy Council, 2004. Renewable Energy Target for Europe $20 \%$ by 2020 . < http://www.erecrenewables.org/fileadmin/erec_docs/Documents/Publications/EREC_Targets_2020_def.p df $>$

[10] EREC, European Renewable Energy Council, 2006. Renewable Energy Scenario to 2040, Half of the global energy supply from renewables in 2040. $<$ http://www.censolar.es/erec2040.pdf >

[11]M. A. Green, K. Emery, Y. Hishikawa, W. Warta, Solar cell efficiency tables (Version 36), Progress in Photovoltaics: Research and Applications, 18, 2010, pp. 346-352. 